\title{
CS Research Square \\ Sensitivity of Prostate Cancer Foci using 1.5 T Multiparametric Magnetic Resonance Imaging
}

\section{Suguru Ito}

Yamagata University Faculty of Medicine

SEI NAITO ( $\nabla$ seinaito@med.id.yamagata-u.ac.jp)

Yamagata University https://orcid.org/0000-0002-6104-4344

Takafumi Narisawa

Yamagata University Faculty of Medicine

Mayu Yagi

Yamagata University Faculty of Medicine

Yuta Kurota

Yamagata University Faculty of Medicine

Hidenori Kanno

Yamagata University Faculty of Medicine

Atsushi Yamagishi

Yamagata University Faculty of Medicine

Toshihiko Sakurai

Yamagata University Faculty of Medicine

Hayato Nishida

Yamagata University Faculty of Medicine

Takuya Yamanobe

Yamagata University Faculty of Medicine

Tomoyuki Kato

Yamagata University Faculty of Medicine

Norihiko Tsuchiya

Yamagata University Faculty of Medicine

Research article

Keywords: Prostate cancer, Magnetic resonance imaging, Radical prostatectomy, Index tumor, Clinically significant prostate cancer

Posted Date: September 22nd, 2020

DOI: https://doi.org/10.21203/rs.3.rs-70151/v1

License: () (i) This work is licensed under a Creative Commons Attribution 4.0 International License. Read Full License 


\section{Abstract}

Background: The detection of prostate cancer ( $\mathrm{CaP}$ ) has increasingly being carried out by multiparametric magnetic resonance imaging (mpMRI). Despite many previous studies, the sensitivity for clinically significant CaP (csCaP) was high, information on mpMRI false-negative lesions is limited. Therefore, the aim of this study was to evaluate the use and limitations of mpMRI in CaP.

Methods: A total of $228 \mathrm{CaP}$ foci in 100 patients who underwent 1.5 T mpMRI and radical prostatectomy between December 2015 and June 2017 were retrospectively analyzed. The sensitivities of CaP foci, csCaP, and index tumors (ITs) were measured. Clinically significant CaP was defined into two categories based on the Gleason score (GS): csCaP/GS $\geq 3+4$ (GS $\geq 3+4$ or diameter $>10$ $\mathrm{mm}$ ) and csCaP/GS $\geq 4+3$ (GS $\geq 4+3$ or diameter $>10 \mathrm{~mm}$ ). In addition, the characteristics of false-negative lesions were identified. The Prostate Imaging Reporting and Data System version 2 was used to determine an mpMRI positive lesion, defined as a lesion having a score of $\geq 3$.

Results: The sensitivity of all legions, csCaP/GS $\geq 3+4$, csCaP/GS $\geq 4+3$, and ITs were $61.4 \%, 75.8 \%, 83.0 \%$, and $91 \%$, respectively. There were 91 lesions that were mpMRI false, $40 \%$ of which were csCaP/GS $\geq 3+4$. There were three lesions with a $\mathrm{GS}$ of $\geq 8$ and $\geq 10 \mathrm{~mm}$ in the false-negative results.

Conclusions: $\mathrm{mpMRI}$ can highly detect ITs and csCaP/GS $\geq 4+3$; however, a few large and high-GS CaPs constitute undetectable lesions in $1.5 \mathrm{~T}$ mpMRI.

\section{Background}

Prostate cancer ( $\mathrm{CaP})$ is the second most prevalent cancer and fifth common cause of cancer death among men worldwide[1]. Currently, $\mathrm{CaP}$ is diagnosed using prostate-specific antigen level, digital rectal examination, and transrectal ultrasound-guided systemic biopsy as a standard care. However, overdiagnosis of insignificant CaP and misdiagnosis of clinically significant cancer (csCaP) can result from these strategies.

In recent years, after the emergence of multiparametric magnetic resonance imaging (mpMRI), the use of MRI in CaP has increased considerably. Previously, the capability of prostate MRI, which was assessed using T1- and T2-weighted imaging (T2WI), to detect $\mathrm{CaP}$ was limited. However, there have been improvements in the detection of CaP through multiparametric MRI, which combines anatomic T2WI with functional and physiologic assessment, including diffusion-weighted imaging (DWI) and its derivative, apparent-diffusion coefficient, dynamic contrast-enhanced (DCE) MRI, and, sometimes, other techniques such as in vivo magnetic resonance proton spectroscopy[2-16]. However, information on mpMRI false-negative lesions in previous reports is limited, and in most of these studies, 3 T mpMRI was used. Nevertheless, 1.5 T MRI was still used.

Therefore, we aimed to analyze the sensitivities of $1.5 \mathrm{~T}$ mpMRI without endorectal coil using radical prostatectomy (RP) specimens. In particular, we examined the details of false-negative lesions.

\section{Methods}

\section{Patients}

Men who underwent RP in Yamagata University Hospital between December 2015 and June 2017 were included in this study. Patients who received androgen deprivation therapy and transurethral resection of prostate before surgery were excluded.

\section{mpMRI}

All patients underwent 1.5 T mpMRI without endorectal coil before prostate biopsy. The orientation of the DWI and DCE MRI was the same as for the T2WI. Prostate Imaging Reporting and Data System version 2 (PI-RADS v2) was used to evaluate the images obtained and were scored as follows: 1 , clinically significant disease highly unlikely to be present; 2 , clinically significant cancer unlikely to be present; 3 , the presence of clinically significant cancer is equivocal; 4 , clinically significant cancer likely to be present; 
and 5, clinically significant cancer highly likely to be present[17]. Basically, an mpMRI positive lesion was defined as a lesion with a score of $\geq 3$ in the PI-RADS v2.

\section{Pathological analysis}

Whole prostate specimens were fixed in $10 \%$ buffered formaldehyde for $48 \mathrm{~h}$, after which the specimens were sectioned perpendicular to the urethra in 4-6-mm serial axial slices and embedded into paraffin (FFPE block). A 5- $\mu$ m-thick FFPE section was mounted on glass slides and stained with hematoxylin and eosin.

Each major cancer foci was evaluated for Gleason score (GS), largest size (mm), extra-prostatic extension (EPE), and surgical margin (SM). For each patient, up to three foci were always evaluated, but beyond that, minimal lesions were excluded.

IT was defined as a lesion having a maximum foci or a high GS within $5 \mathrm{~mm}$ of the maximum, which is considered to reflect mainly the prognosis $[18,19]$. Prostate cancer was categorized into two groups: csCaP/GS $\geq 3+4(G S \geq 3+4$ or diameter $>10 \mathrm{~mm})$ and $\mathrm{csCaP} / \mathrm{GS} \geq 4+3$ (GS $\geq 4+3$ or diameter $>10 \mathrm{~mm})$.

\section{Statistical analyses}

Differences were compared using the Welch $t$ test and the Fisher test, and the free statistical software package $\mathrm{R}$ version 3.5.2 (https://cran.r-project.org) was used to perform all statistical analyses.

\section{Results}

\section{Clinicopathological characteristics}

The characteristics of the 100 patients who underwent mpMRI before prostate biopsy and RP (96 robot-assisted and 4 open) are shown in Table 1. The following characteristics were found for the patients (median [range]): age, 67 years (52-78 years); prostatespecific antigen level, $7.14 \mathrm{ng} / \mathrm{ml}(3.33-28.24 \mathrm{ng} / \mathrm{ml})$; and prostate volume, $36.0 \mathrm{~g}(19.5-74.0 \mathrm{~g})$. According to National Comprehensive Cancer Network guidelines, of the 100 patients, 11, 60, and 29 were classified into low, intermediate, and poor risk, respectively. 
Table 1

Patient characteristics

\begin{tabular}{|c|c|}
\hline Number & 100 \\
\hline Age, median (range) & $67(52-78)$ \\
\hline Prostate-specific antigen, median (range), (ng/ml) & $7.14(3.33-28.24)$ \\
\hline \multicolumn{2}{|l|}{ Clinical stage, n (\%) } \\
\hline cT1c & 4 \\
\hline cT2a & 33 \\
\hline cT2b & 13 \\
\hline cT2c & 45 \\
\hline ст3а & 4 \\
\hline \multicolumn{2}{|l|}{ Surgical approach, $\mathrm{n}$} \\
\hline robotic-assisted & 96 \\
\hline open & 4 \\
\hline \multicolumn{2}{|l|}{ Risk category*, n } \\
\hline low & 11 \\
\hline intermediate & 60 \\
\hline high & 29 \\
\hline Prostate volume, median (range), (g) & $36.0(19.5-74.0)$ \\
\hline \multicolumn{2}{|l|}{ Pathological stage, n (\%) } \\
\hline pT2a & 11 \\
\hline pT2b & 1 \\
\hline pT2c & 47 \\
\hline pT3a & 29 \\
\hline pT3b & 5 \\
\hline undetectable & 7 \\
\hline \multicolumn{2}{|l|}{ EPE, $n$} \\
\hline negative & 52 \\
\hline positive & 34 \\
\hline undetectable & 14 \\
\hline \multicolumn{2}{|l|}{ SM, n } \\
\hline negative & 66 \\
\hline positive & 24 \\
\hline undetectable & 10 \\
\hline
\end{tabular}


Data on a total of 228 tumor foci that were detected in tumors in the 100 RP specimens are shown in Table 2. GS was 6 in 94 (41.2\%), $3+4$ in 72 (31.5\%), $4+3$ in 27 (11.8\%), and $\geq 8$ in 35 (15.4\%) specimens. As for tumor location, $153(67.1 \%)$ and 75 (32.8\%) tumors were located in the peripheral and transition zones, respectively. Moreover, positive rates of EPE and SM were higher in IT $(n=100)$ than in non-IT $(n=128)(p<0.001)$ (Table 2).

Table 2

Characteristics of the individual tumor foci on prostatectomy specimen

\begin{tabular}{|c|c|c|c|c|}
\hline & All lesions & Index tumor* & Non-index tumor & P value ${ }^{\dagger}$ \\
\hline Number & 228 & 100 & 128 & \\
\hline \multicolumn{5}{|l|}{ Gleason score, n (\%) } \\
\hline 6 & $94(41.2 \%)$ & $13(13.0 \%)$ & $81(63.2 \%)$ & $<0.001$ \\
\hline $3+4$ & $72(31.5 \%)$ & $43(43.0 \%)$ & $29(22.6 \%)$ & $<0.001$ \\
\hline $3+5$ & $3(1.3 \%)$ & $3(3.0 \%)$ & $0(0.0 \%)$ & 0.048 \\
\hline $4+3$ & $27(11.8 \%)$ & $16(16.0 \%)$ & $11(8.7 \%)$ & 0.085 \\
\hline $4+4$ & $6(2.6 \%)$ & $4(4.0 \%)$ & $2(1.5 \%)$ & 0.256 \\
\hline $4+5$ & $19(8.3 \%)$ & $16(16.0 \%)$ & $3(2.3 \%)$ & 0.0015 \\
\hline $5+3$ & $3(1.3 \%)$ & $1(1.0 \%)$ & $2(1.5 \%)$ & 0.713 \\
\hline $5+4$ & $4(1.7 \%)$ & $4(4.0 \%)$ & $0(0.0 \%)$ & 0.024 \\
\hline \multicolumn{5}{|l|}{ Location, n (\%) } \\
\hline Peripheral zone & $153(67.1 \%)$ & $62(62.0 \%)$ & $91(71.1 \%)$ & 0.148 \\
\hline Right peripheral zone & $83(36.4 \%)$ & $33(33.0 \%)$ & $50(39.0 \%)$ & 0.347 \\
\hline Left peripheral zone & $58(25.4 \%)$ & $18(18.0 \%)$ & $40(31.2 \%)$ & 0.031 \\
\hline Both peripheral zone & $12(5.2 \%)$ & $11(11.0 \%)$ & $1(0.7 \%)$ & $<0.001$ \\
\hline Transitional zone & $75(32.8 \%)$ & $38(38.0 \%)$ & $37(28.9 \%)$ & 0.148 \\
\hline Right transitional zone & $20(8.7 \%)$ & $4(4.0 \%)$ & $16(12.5 \%)$ & 0.0153 \\
\hline Left transitional zone & $28(12.2 \%)$ & $9(9.0 \%)$ & 19 (14.9\%) & 0.184 \\
\hline Both transitional zone & $27(11.8 \%)$ & $25(25.0 \%)$ & $2(1.5 \%)$ & $<0.001$ \\
\hline \multicolumn{5}{|l|}{ EPE, n (\%) } \\
\hline negative & $176(77.1 \%)$ & $52(52.0 \%)$ & $126(98.5 \%)$ & $<0.001$ \\
\hline positive & $36(15.7 \%)$ & $34(34.0 \%)$ & $2(1.5 \%)$ & $<0.001$ \\
\hline undetectable & $14(6.1 \%)$ & $14(14.0 \%)$ & $0(0.0 \%)$ & 0.0016 \\
\hline \multicolumn{5}{|l|}{ SM, n (\%) } \\
\hline negative & $192(84.2 \%)$ & $66(66.0 \%)$ & $126(98.5 \%)$ & $<0.001$ \\
\hline positive & $24(10.5 \%)$ & $24(24.0 \%)$ & $0(0.0 \%)$ & $<0.001$ \\
\hline undetectable & $12(5.2 \%)$ & $10(10.0 \%)$ & $2(1.5 \%)$ & 0.002 \\
\hline
\end{tabular}




\section{Sensitivity of mpMRI}

The sensitivity of all 228 lesions was $61.4 \%$. The ITs, csCaP/GS $\geq 4+3$, diameter $>10 \mathrm{~mm}$, and GS $\geq 8$ had relatively high sensitivities (91.0\%, 85.3\%, 85.7\%, and $85.7 \%$, respectively). There lesions with a diameter $<10 \mathrm{~mm}$, especially in the specimens with low GS had low sensitivities (diameter $<10 \mathrm{~mm}$, diameter $<10 \mathrm{~mm}$ and GS 6, diameter $<10 \mathrm{~mm}$, and GS $3+4$ had sensitivities of $31.1 \%, 24.6 \%$, and $31.6 \%$, respectively). Although lesions with a GS of 6 had low sensitivities (36.1\%), lesions with a diameter of $\geq 10 \mathrm{~mm}$ were highly detected even in GS 6 (76.2\%). Positive EPE and positive SM had relatively high sensitivities as well (91.7\% and $79.2 \%$, respectively). Approximately half of the lesions (48.2\%) was mpMRI positive lesion. Whereas $72.2 \%$ of the lesions with a diameter $>10 \mathrm{~mm}$ were diagnosed, only $22.0 \%$ of the lesions with a diameter of $\leq 10 \mathrm{~mm}$ were diagnosed (Table 3 ). 
Table 3

Sensitivity of multiparametric magnetic resonance imaging for detection of prostatectomy pathology parameters

\begin{tabular}{|c|c|c|c|}
\hline & \multirow[t]{2}{*}{ Number } & \multicolumn{2}{|l|}{ Sensitivity } \\
\hline & & score $\geq 3$ on PI-RADS v2 & score $\geq 4$ on PI-RADS v2 \\
\hline All & 228 & $61.4 \%$ & $48.2 \%$ \\
\hline Index tumor* & 100 & $91.0 \%$ & $77.0 \%$ \\
\hline Maximum lesion & 100 & $90.0 \%$ & $76.0 \%$ \\
\hline $\mathrm{csCaP} / \mathrm{GS} \geq 3+4^{\dagger}$ & 157 & $77.7 \%$ & $63.1 \%$ \\
\hline $\operatorname{csCaP} / G S \geq 4+3^{\ddagger}$ & 136 & $85.3 \%$ & $70.0 \%$ \\
\hline \multicolumn{4}{|l|}{ Diameter } \\
\hline$\leq 5 \mathrm{~mm}$ & 67 & $20.8 \%$ & $11.9 \%$ \\
\hline$>5 \mathrm{~mm}, \leq 10 \mathrm{~mm}$ & 42 & $47.6 \%$ & $38.0 \%$ \\
\hline$>10 \mathrm{~mm}$ & 119 & $85.7 \%$ & $72.2 \%$ \\
\hline \multicolumn{4}{|l|}{ Gleason score } \\
\hline 6 & 94 & $36.1 \%$ & $25.5 \%$ \\
\hline $3+4$ & 72 & $64.4 \%$ & $56.9 \%$ \\
\hline $4+3$ & 27 & $74.0 \%$ & $62.9 \%$ \\
\hline$\geq 8$ & 35 & $85.7 \%$ & $74.2 \%$ \\
\hline \multicolumn{4}{|c|}{ Diameter and Gleason score } \\
\hline \multicolumn{4}{|c|}{$\leq 10 \mathrm{~mm}$ and Gleason score } \\
\hline 6 & 73 & $24.6 \%$ & $15.1 \%$ \\
\hline $3+4$ & 19 & $31.6 \%$ & $21.1 \%$ \\
\hline $4+3$ & 11 & $54.5 \%$ & $45.5 \%$ \\
\hline$\geq 8$ & 6 & $66.7 \%$ & $66.7 \%$ \\
\hline \multicolumn{4}{|c|}{$>10 \mathrm{~mm}$ and Gleason score } \\
\hline 6 & 21 & $76.2 \%$ & $61.9 \%$ \\
\hline $3+4$ & 53 & $83.0 \%$ & $69.8 \%$ \\
\hline $4+3$ & 16 & $100.0 \%$ & $87.5 \%$ \\
\hline$\geq 8$ & 29 & $89.7 \%$ & $75.9 \%$ \\
\hline \multicolumn{4}{|l|}{ EPE } \\
\hline positive & 36 & $91.7 \%$ & $77.8 \%$ \\
\hline negative & 192 & $53.6 \%$ & $42.7 \%$ \\
\hline \multicolumn{4}{|l|}{ SM } \\
\hline positive & 24 & $79.2 \%$ & $70.8 \%$ \\
\hline negative & 209 & $57.8 \%$ & $46.6 \%$ \\
\hline
\end{tabular}




\section{Characteristics of mpMRI false-negative lesions}

There were 91 (39.9\%) mpMRI false-negative lesions, 58 and 33 of which were classified as PI-RADS score 1 and 2, respectively. Surprisingly, $40.7 \%$ of $\mathrm{mpMRI}$ false-negative lesions were csCaP/GS $\geq 3+4$, and $51.5 \%$ of score 2 lesions were csCaP/GS $\geq 4+3$. Although only five lesions (5.5\%) were GS $\geq 8$, three of these had diameters $\geq 10 \mathrm{~mm}$ (Table 4). Of the nine mpMRI false-negative ITs, seven were GS $\leq 3+4$; however, two lesions were large and GS $4+5$ (Table 5). 
Table 4

Characteristics of multiparametric magnetic resonance imaging false-negative lesions

\begin{tabular}{|c|c|c|c|}
\hline & $\begin{array}{l}\text { PI-RADS v2 score } 1 \\
\text { (58 lesions) }\end{array}$ & $\begin{array}{l}\text { PI-RADS v2 score } 2 \\
\text { (33 lesions) }\end{array}$ & $\begin{array}{l}\text { Total } \\
\text { (91 lesions) }\end{array}$ \\
\hline Index tumor* & $3(5.2 \%)$ & $6(18.2 \%)$ & $9(9.9 \%)$ \\
\hline $\mathrm{csCaP} / \mathrm{GS} \geq 3+4^{\dagger}$ & $17(29.3 \%)$ & $20(34.5 \%)$ & $37(40.7 \%)$ \\
\hline $\mathrm{csCaP} / \mathrm{GS} \geq 4+3^{\ddagger}$ & $7(12.1 \%)$ & $17(51.5 \%)$ & $24(26.4 \%)$ \\
\hline \multicolumn{4}{|l|}{ Diameter (mm) } \\
\hline$\leq 5$ & $42(72.4 \%)$ & $10(30.3 \%)$ & $52(57.1 \%)$ \\
\hline$>5, \leq 10$ & $12(20.7 \%)$ & $10(30.3 \%)$ & $22(24.2 \%)$ \\
\hline$>10$ & $4(6.9 \%)$ & $13(39.4 \%)$ & $17(18.7 \%)$ \\
\hline \multicolumn{4}{|l|}{ GS } \\
\hline 6 & $44(75.9 \%)$ & $15(45.6 \%)$ & $59(64.8 \%)$ \\
\hline $3+4$ & $10(17.2 \%)$ & $12(36.4 \%)$ & $22(24.2 \%)$ \\
\hline $4+3$ & $2(3.44 \%)$ & $3(9.0 \%)$ & $5(5.5 \%)$ \\
\hline$\geq 8$ & $2(3.44 \%)$ & $3(9.0 \%)$ & $5(5.5 \%)$ \\
\hline \multicolumn{4}{|c|}{ Diameter and Gleason score } \\
\hline \multicolumn{4}{|c|}{$\leq 10 \mathrm{~mm}$ and Gleason score } \\
\hline 6 & $41(70.7 \%)$ & $13(39.4 \%)$ & $54(59.3 \%)$ \\
\hline $3+4$ & $10(17.2 \%)$ & $3(9.0 \%)$ & $13(14.3 \%)$ \\
\hline $4+3$ & $2(3.4 \%)$ & $3(9.0 \%)$ & $5(5.5 \%)$ \\
\hline$\geq 8$ & $1(1.7 \%)$ & $1(3.0 \%)$ & $2(2.2 \%)$ \\
\hline \multicolumn{4}{|c|}{$>10 \mathrm{~mm}$ and Gleason score } \\
\hline 6 & $3(5.2 \%)$ & $2(6.1 \%)$ & $5(5.5 \%)$ \\
\hline $3+4$ & $0(0.0 \%)$ & $9(27.3 \%)$ & $9(9.9 \%)$ \\
\hline $4+3$ & $0(0.0 \%)$ & $0(0.0 \%)$ & $0(0.0 \%)$ \\
\hline$\geq 8$ & $1(1.7 \%)$ & $2(6.1 \%)$ & $3(3.3 \%)$ \\
\hline \multicolumn{4}{|l|}{ EPE, n (\%) } \\
\hline negative & 57 (98.2\%) & 31 (93.9\%) & 88 (96.7\%) \\
\hline positive & 1 (1.8\%) & 2 (6.1\%) & 3 (3.3\%) \\
\hline \multicolumn{4}{|l|}{ SM, n (\%) } \\
\hline negative & 57 (98.2\%) & 29 (87.9\%) & 86 (94.5\%) \\
\hline positive & $1(1.8 \%)$ & $4(12.1 \%)$ & 5 (5.5\%) \\
\hline \multicolumn{4}{|c|}{$\begin{array}{l}\text { *Index tumor was defined as a lesion having a maximal focus or a high Gleason score within } 5 \mathrm{~mm} \text { of the maximum. } \\
{ }^{\dagger} \mathrm{csCaP} / \mathrm{GS} \geq 3+4 ; \text { clinically significant prostate cancer (Gleason score } \geq 3+4 \text { or diameter }>10 \mathrm{~mm} \text { ), }{ }^{\ddagger} \mathrm{csCaP} / \mathrm{GS} \geq 4+3 \text {; } \\
\text { clinically significant prostate cancer (Gleason score } \geq 4+3 \text { or diameter }>10 \mathrm{~mm} \text { ) } \\
\text { Abbreviation: PI-RADS v2; Prostate Imaging and Reporting and Data System version 2, EPE; extra-prostatic extension, SM; } \\
\text { surgical margin }\end{array}$} \\
\hline
\end{tabular}


Table 5

Characteristic of magnetic resonance imaging negative lesions in index tumor*

\begin{tabular}{|c|c|c|c|c|c|c|c|c|c|c|c|c|}
\hline \multirow{2}{*}{$\begin{array}{l}\text { Age } \\
\text { (y) }\end{array}$} & \multirow{2}{*}{$\begin{array}{l}\text { PSA } \\
(n g / m l)\end{array}$} & \multirow{2}{*}{$\begin{array}{l}\text { PV } \\
\text { (g) }\end{array}$} & \multirow[t]{2}{*}{ Location } & \multicolumn{4}{|c|}{ PI-RADS v2 } & \multirow[t]{2}{*}{ GS } & \multirow[t]{2}{*}{ EPE } & \multirow[t]{2}{*}{ SM } & \multirow{2}{*}{$\begin{array}{l}\text { Solitary or } \\
\text { multifocal }\end{array}$} & \multirow{2}{*}{$\begin{array}{l}\text { Diameter } \\
(\mathrm{mm})\end{array}$} \\
\hline & & & & T2WI & DWI & DCE & score & & & & & \\
\hline 70 & 10.6 & 67 & $\mathrm{PZ}$ & 4 & 2 & positive & 2 & $\begin{array}{l}4 \\
+ \\
5\end{array}$ & negative & negative & multifocal & 20 \\
\hline 65 & 4.7 & 61 & PZ & 1 & 1 & positive & 1 & 6 & negative & negative & multifocal & 2 \\
\hline 66 & 5.4 & 36 & PZ & 2 & 2 & $x$ & 2 & $\begin{array}{l}3 \\
+ \\
4\end{array}$ & positive & positive & multifocal & 27 \\
\hline 69 & 4.4 & 65 & $\mathrm{TZ}$ & 2 & 2 & positive & 2 & $\begin{array}{l}3 \\
+ \\
4\end{array}$ & unknown & positive & multifocal & 20 \\
\hline 64 & 12.7 & 70 & $\mathrm{TZ}$ & 1 & 1 & negative & 1 & 6 & positive & positive & multifocal & 14 \\
\hline 67 & 10.4 & 31 & $\mathrm{PZ}$ & 3 & 2 & negative & 2 & $\begin{array}{l}4 \\
+ \\
5\end{array}$ & positive & positive & multifocal & 23 \\
\hline 60 & 10.8 & 26 & $\mathrm{TZ}$ & 2 & 3 & negative & 2 & $\begin{array}{l}3 \\
+ \\
4\end{array}$ & negative & negative & multifocal & 17 \\
\hline 63 & 4.8 & 42 & $\mathrm{PZ}$ & 2 & 2 & negative & 2 & 6 & negative & negative & solitary & 7 \\
\hline 69 & 8.2 & 57 & $\mathrm{TZ}$ & 1 & 1 & negative & 1 & 6 & negative & negative & solitary & 7 \\
\hline $\begin{array}{l}\text { *Innc } \\
\text { Abbr } \\
\text { Syst } \\
\text { Glea }\end{array}$ & $\begin{array}{l}\text { tumor } \\
\text { ations: } \\
\text { version } \\
\text { n score, }\end{array}$ & $p$ & $\begin{array}{l}\text { d as a les } \\
\text { tatate spe } \\
\text { T2-weight } \\
\text {-prostatic }\end{array}$ & $\begin{array}{l}\text { n hav } \\
\text { ic ant } \\
\text { imag } \\
\text { ttensi }\end{array}$ & $\begin{array}{l}\text { a m } \\
\text { n, PI } \\
\text { DW }\end{array}$ & $\begin{array}{l}\text { mum foci } \\
\text { rostate vo } \\
\text { iffusion w } \\
\text { rgical mar }\end{array}$ & $\begin{array}{l}\text { a hic } \\
\text { me, P } \\
\text { ghted }\end{array}$ & $\begin{array}{l}\text { Alea } \\
\text { ADS }\end{array}$ & $\begin{array}{l}\text { score w } \\
\text { 'Prostate } \\
\text { DCE; dyn } \\
\text { al zone, T }\end{array}$ & $\begin{array}{l}\mathrm{n} 5 \mathrm{~mm} c \\
\text { laging an } \\
\text { ic constr } \\
\text { transition }\end{array}$ & $\begin{array}{l}\text { he maximu } \\
\text { Reporting a } \\
\text { t enhanced, } \\
\text { one }\end{array}$ & Data \\
\hline
\end{tabular}

\section{Sensitivity of pT3}

Lesions that were upgraded to pT3 are shown in Table 6 . Only four (11.8\%) cases of 13 pT3 were diagnosed as cT3 by mpMRI. On the other hand, all pT3 were diagnosed as cT3 by mpMRI.

Table 6

Upgraded lesion to pT3

\begin{tabular}{|lll|}
\hline Clinical Stage & Pathological Stage & number \\
\hline cT1c & pT3a & 3 \\
cT2a & pT3a & 5 \\
\hline cT2b & pT3b & 1 \\
\hline cT2c & pT3a & 5 \\
\hline & рT3a & 1 \\
\hline
\end{tabular}

\section{Discussion}

The overall results of this study are similar to those of previous studies. The sensitivity of all lesions with a PI-RADS score of $\geq 3$ was $61.4 \%$ in this study and $31-62 \%$ in previous studies that used RP specimens (Table 3$)[6,10,15,20]$. The low sensitivity of all 
lesions reflects the low sensitivity of small and low-GS lesions. However, even in GS $\geq 8, \mathrm{mpMRI}$ misdiagnosed one-third of the lesions with diameters of $\leq 10 \mathrm{~mm}$. In lesions with GS $3+4$ and diameter $\leq 10 \mathrm{~mm}$, the sensitivity was only $31.6 \%$, which caused the low sensitivity of csCaP/GS $\geq 3+4$ (77.7\%) (Table 3 ). Detection rates for csCaP/GS $\geq 3+4(67-75 \%)$ in previous studies were similar.

csCaP is usually defined as lesions with GS $\geq 3+4$ or diameter $>10 \mathrm{~mm}[21]$. However, National Comprehensive Cancer Network guidelines also recommend active surveillance for GS $3+4$ lesions. In addition, some recent studies have defined GS $\geq 4+3$ as $\operatorname{csCaP}[8]$. Therefore, we used two types in the analysis of csCaP. Compared with csCaP/GS $\geq 3+4$, the sensitivity of $\operatorname{csCaP} / G S \geq 4$ +3 in this study (85.7\%) and in previous studies (91-95\%) was relatively high[8] [22] (Table 3).

It has been suggested in recent reports that lesions associated with cancer progression and metastasis could be the largest lesions in prostate or highest GS within 5 mm of maximum, called IT[18] [19]. Focal therapy for limited CaP is rationally based on IT hypothesis. Multiparametric MRI, which might be considered a suitable tool for IT detection, has a high detection rate for IT ( $91 \%$ in this study and $80-91 \%$ in the previous studies). Nevertheless, the approximately $10 \%$ rate of misdiagnosis needs our attention (Table 3).

Tumors undetected in mpMRI are often characterized as small and multifocal[23]. Ninety-one (39.9\%) lesions in this study were mpMRI negative, 67 (73.6\%) of which were insignificant cancers (GS $\leq 3+4$ and $\leq 10 \mathrm{~mm}$ ) (Table 4). In case of IT, most undiagnosed lesions were multifocal cancers. However, it was surprising that two cases had an IT with $\geq 20 \mathrm{~mm}$ and GS $4+5$. A previous study using mainly $3 \mathrm{~T}$ mpMRI mentioned that mpMRI negative lesions could be high GS, but large lesions with a high GS were fully detectable[4]. The intensity of the applied magnetic field may be reason for the missing cases with high-grade and large lesions in our study. In a study by Ulrich et al., the correlation between 1.5 and $3 \mathrm{~T}$ within the same patients was reported. This study revealed that comparable objective image quality is revealed by $1.5 \mathrm{~T}$ MRI in T2WI but is inferior to $3 \mathrm{~T}$ in DWI. The conclusions of the study indicated feasible diagnostic performance even in 1.5 T MRI[24]. However, the inferiority of 1.5 T MRI in DWI might lead to the misdiagnoses in this study.

Positive SM is an important factor that reflects the postoperative outcome[25] [26]. Postoperative functional outcomes, including continence and erectile function, are improved by neurovascular bundle preservation techniques[27] [28], which potentially increase positive SM when neurovascular bundle is preserved on the EPE positive side. Although mpMRI is mainly used to predict EPE before surgery, previous reports have mentioned that the sensitivity of EPE is not enough. A meta-analysis showed a sensitivity of $57 \%$ and a specificity of $91 \%$ for microscopic EPE[29]. The sensitivity and specificity in this study were only $11.8 \%$ and $100 \%$, respectively (Table 6). Positive mpMRI lesions had more positive EPE and SM than mpMRI negative lesions (Table 3).

Several limitations of this study should be mentioned. First, this was a retrospective study. Second, the PI-RADS score was estimated by a single physician. Several studies have revealed that there are diagnostic differences across readers[10, 30]. Third, there could be differences in characteristics between patients who underwent RP in this study and those who underwent other treatments. Fourth, up to three lesions were always evaluated; however, minimal lesions beyond these three were excluded from this analysis.

\section{Conclusions}

Detection of IT and csCaP/GS $\geq 4+3$ through mpMRI is high; however, large and high-GS CaPs are sometimes undetected in $1.5 \mathrm{~T}$ mpMRI.

\section{Abbreviations}

CaP; prostate cancer, csCaP; clinically significant prostate cancer, MRI; magnetic resonance imaging, mpMRI; multiparametric magnetic resonance imaging, T2Wl; T2-weighted imaging, DWl; diffusion-weighted imaging, DCE; dynamic contrast-enhanced, RP; radical prostatectomy, PI-RADS v2; Prostate Imaging Reporting and Data System version 2, GS; Gleason score, EPE; extra-prostatic extension, SM; surgical margin.

\section{Declarations}




\section{Ethics approval and consent to participate}

The ethics committee of Yamagata University Faculty of Medicine approved the study (approval no.H28-34). The methods were conducted in accordance with the approved guidelines. All participates in this study have consented to participate with written consent form.

\section{Availability of data and materials}

The datasets during and/or analyzed during the current study available from the corresponding author on reasonable request.

\section{Competing interests}

The authors declare no conflict of interest.

\section{Funding}

None.

\section{Authors' contributions}

SI, SN, TK, and NT participated in the design of the present study. SI drafted the manuscript and figures. SI performed statistical analyses. TN, MY, YK, HK, AY, TS, HN, and TY collected data. SN, TK, and NT participated in the coordination and helped with the drafting of the manuscript. All authors have read and approved the final manuscript.

\section{Acknowledgements}

We would like to thank Enago (www.enago.jp) for the English language editing.

\section{References}

1. Culp MB, Soerjomataram I, Efstathiou JA, Bray F, Jemal A. Recent Global Patterns in Prostate Cancer Incidence and Mortality Rates. Eur Urol 2019.

2. Turkbey B, Mani H, Shah V, Rastinehad AR, Bernardo M, Pohida T, Pang Y, Daar D, Benjamin C, McKinney YL, et al. Multiparametric $3 \mathrm{~T}$ prostate magnetic resonance imaging to detect cancer: histopathological correlation using prostatectomy specimens processed in customized magnetic resonance imaging based molds. J Urol. 2011;186(5):1818-24.

3. Isebaert S, Van den Bergh L, Haustermans K, Joniau S, Lerut E, De Wever L, De Keyzer F, Budiharto T, Slagmolen P, Van Poppel $\mathrm{H}$, et al. Multiparametric MRI for prostate cancer localization in correlation to whole-mount histopathology. J Magn Reson Imaging. 2013;37(6):1392-401.

4. Bratan F, Niaf E, Melodelima C, Chesnais AL, Souchon R, Mege-Lechevallier F, Colombel M, Rouviere O. Influence of imaging and histological factors on prostate cancer detection and localisation on multiparametric MRI: a prospective study. European radiology. 2013;23(7):2019-29.

5. Delongchamps NB, Lefevre A, Bouazza N, Beuvon F, Legman P, Cornud F: Detection of significant prostate cancer with magnetic resonance targeted biopsies-should transrectal ultrasound-magnetic resonance imaging fusion guided biopsies alone be a standard of care? J Urol 2015, 193(4):1198-1204.

6. Le JD, Tan N, Shkolyar E, Lu DY, Kwan L, Marks LS, Huang J, Margolis DJ, Raman SS, Reiter RE. Multifocality and prostate cancer detection by multiparametric magnetic resonance imaging: correlation with whole-mount histopathology. Eur Urol. 2015;67(3):569-76. 
7. Radtke JP, Schwab C, Wolf MB, Freitag MT, Alt CD, Kesch C, Popeneciu IV, Huettenbrink C, Gasch C, Klein T, et al. Multiparametric Magnetic Resonance Imaging (MRI) and MRI-Transrectal Ultrasound Fusion Biopsy for Index Tumor Detection: Correlation with Radical Prostatectomy Specimen. Eur Urol. 2016;70(5):846-53.

8. Vargas HA, Hotker AM, Goldman DA, Moskowitz CS, Gondo T, Matsumoto K, Ehdaie B, Woo S, Fine SW, Reuter VE, et al. Updated prostate imaging reporting and data system (PIRADS v2) recommendations for the detection of clinically significant prostate cancer using multiparametric MRI: critical evaluation using whole-mount pathology as standard of reference. European radiology. 2016;26(6):1606-12.

9. Weinreb JC, Barentsz JO, Choyke PL, Cornud F, Haider MA, Macura KJ, Margolis D, Schnall MD, Shtern F, Tempany CM, et al. PIRADS Prostate Imaging - Reporting and Data System: 2015, Version 2. Eur Urol. 2016;69(1):16-40.

10. Greer MD, Brown AM, Shih JH, Summers RM, Marko J, Law YM, Sankineni S, George AK, Merino MJ, Pinto PA, et al. Accuracy and agreement of PIRADSv2 for prostate cancer mpMRI: A multireader study. J Magn Reson Imaging. 2017;45(2):579-85.

11. Woo S, Suh CH, Kim SY, Cho JY, Kim SH: Diagnostic Performance of Prostate Imaging Reporting and Data System Version 2 for Detection of Prostate Cancer. A Systematic Review and Diagnostic Meta-analysis. Eur Urol 2017, 72(2):177-188.

12. Zhang L, Tang M, Chen S, Lei X, Zhang X, Huan Y. A meta-analysis of use of Prostate Imaging Reporting and Data System Version 2 (PI-RADS V2) with multiparametric MR imaging for the detection of prostate cancer. European radiology. 2017;27(12):5204-14.

13. Borofsky S, George AK, Gaur S, Bernardo M, Greer MD, Mertan FV, Taffel M, Moreno V, Merino MJ, Wood BJ, et al. What Are We Missing? False-Negative Cancers at Multiparametric MR Imaging of the Prostate. Radiology. 2018;286(1):186-95.

14. Porpiglia F, Checcucci SDEL, Garrou E, Manfredi D, Mele M, Pecoraro F, Passera A, Bollito R, Fiori E. C: Comparing Image-guided targeted Biopsies to Radical Prostatectomy Specimens for Accurate Characterization of the Index Tumor in Prostate Cancer. Anticancer research. 2018;38(5):3043-7.

15. Girometti R, Giannarini G, Greco F, Isola M, Cereser L, Como G, Sioletic S, Pizzolitto S, Crestani A, Ficarra V, et al. Interreader agreement of PI-RADS v. 2 in assessing prostate cancer with multiparametric MRI: A study using whole-mount histology as the standard of reference. J Magn Reson Imaging. 2019;49(2):546-55.

16. Kim R, Kim CK, Park JJ, Kim JH, Seo SI, Jeon SS, Lee HM. Prognostic Significance for Long-Term Outcomes Following Radical Prostatectomy in Men with Prostate Cancer: Evaluation with Prostate Imaging Reporting and Data System Version 2. Korean J Radiol. 2019;20(2):256-64.

17. Barrett T, Turkbey B, Choyke PL. PI-RADS version 2: what you need to know. Clinical radiology. 2015;70(11):1165-76.

18. Bott SR, Ahmed HU, Hindley RG, Abdul-Rahman A, Freeman A, Emberton M. The index lesion and focal therapy: an analysis of the pathological characteristics of prostate cancer. BJU Int. 2010;106(11):1607-11.

19. Ahmed HU, Arya M, Freeman A, Emberton M. Do low-grade and low-volume prostate cancers bear the hallmarks of malignancy? Lancet Oncol. 2012;13(11):e509-17.

20. Truong M, Hollenberg G, Weinberg E, Messing EM, Miyamoto H, Frye TP. Impact of Gleason Subtype on Prostate Cancer Detection Using Multiparametric Magnetic Resonance Imaging: Correlation with Final Histopathology. J Urol 2017.

21. Ploussard G, Epstein JI, Montironi R, Carroll PR, Wirth M, Grimm MO, Bjartell AS, Montorsi F, Freedland SJ, Erbersdobler A, et al. The contemporary concept of significant versus insignificant prostate cancer. Eur Urol. 2011;60(2):291-303.

22. Johnson DC, Raman SS, Mirak SA, Kwan L, Bajgiran AM, Hsu W, Maehara CK, Ahuja P, Faiena I, Pooli A, et al: Detection of Individual Prostate Cancer Foci via Multiparametric Magnetic Resonance Imaging. Eur Urol 2018.

23. Stabile A, Giganti F, Rosenkrantz AB, Taneja SS, Villeirs G, Gill IS, Allen C, Emberton M, Moore CM, Kasivisvanathan V. Multiparametric MRI for prostate cancer diagnosis: current status and future directions. Nature reviews Urology 2019.

24. Ullrich T, Quentin M, Oelers C, Dietzel F, Sawicki LM, Arsov C, Rabenalt R, Albers P, Antoch G, Blondin D, et al: Magnetic resonance imaging of the prostate at 1.5 versus 3.0T: A prospective comparison study of image quality. Eur J Radio/ 2017 , 90:192-197.

25. Yossepowitch O, Bjartell A, Eastham JA, Graefen M, Guillonneau BD, Karakiewicz PI, Montironi R, Montorsi F. Positive surgical margins in radical prostatectomy: outlining the problem and its long-term consequences. Eur Urol. 2009;55(1):87-99.

26. Roder MA. Radical prostatectomy for clinically localised prostate cancer at Rigshospitalet 1995-2011 - an analysis of surgical and oncological outcome. Danish medical journal. 2013;60(12):B4752.

Page $13 / 14$ 
27. Walsh PC, Donker PJ. Impotence following radical prostatectomy: insight into etiology and prevention. J Urol. 1982;128(3):492-7.

28. Reeves F, Preece P, Kapoor J, Everaerts W, Murphy DG, Corcoran NM, Costello AJ. Preservation of the neurovascular bundles is associated with improved time to continence after radical prostatectomy but not long-term continence rates: results of a systematic review and meta-analysis. Eur Urol. 2015;68(4):692-704.

29. de Rooij M, Hamoen EH, Witjes JA, Barentsz JO, Rovers MM: Accuracy of Magnetic Resonance Imaging for Local Staging of Prostate Cancer: A Diagnostic Meta-analysis. Eur Urol 2016, 70(2):233-245.

30. Park SY, Jung DC, Oh YT, Cho NH, Choi YD, Rha KH, Hong SJ, Han K. Prostate Cancer: PI-RADS Version 2 Helps Preoperatively Predict Clinically Significant Cancers. Radiology. 2016;280(1):108-16. 